\title{
Pengaruh E-WOM Facebook dan Brand Trust terhadap Pembentukan Brand Attachment Produk Online di Kota Bima
}

\author{
Ismunandar ${ }^{\varpi_{1}}$, Sri Ernawati ${ }^{2}$ \\ Department Of Management, Sekolah Tinggi Ilmu Ekonomi Bima \\ DOI : https://doi.org/10.37531/ecotal.v1i2.18
}

\begin{abstract}
ABSTRAK
Populasi dalam penelitian ini adalah konsumen di Kota Bima yang memiliki Facebook dan pernah melakukan pembelian online di Facebook yang jumlahnya tidak dapat diukur dengan pasti (populasi tidak diketahui). Sampel dalam penelitian ini berjumlah 100 responden dengan menggunakan teknik purposive sampling. Teknik pengumpulan data menggunakan angket dengan skala likert yang masing-masing telah teruji dan telah memenuhi syarat validitas dan reliabilitas. Hasil analisis regresi linier berganda dengan SPSS versi 20 menunjukkan bahwa EWOM tidak berpengaruh positif dan signifikan terhadap keterikatan merek produk online di Kota Bima, dan kepercayaan merek berpengaruh positif dan signifikan terhadap keterikatan merek produk online di Kota Bima.
\end{abstract}

\section{Kata Kunci:}

Kualitas Produk, Harga, Keputusan Pembelian

\begin{abstract}
The population in this study were consumers in Bima City who owned Facebook and had made online purchases on Facebook whose numbers could not be measured with certainty (population unknown). The sample in this study amounted to 100 respondents using purposive sampling technique. The data collection technique used a questionnaire with a Likert scale, each of which had been tested and had met the validity and reliability requirements. The results of multiple linear regression analysis with SPSS version 20 show that E-WOM has no positive and significant effect on online product brand engagement in Bima City, and brand trust has a positive and significant effect on online product brand engagement in Bima City.
\end{abstract}

Keywords : Product Quality, Price, Purchase Decision

$\triangle$ Corresponding Author :

E-mail address: andar.stiebima@gmail.com (Jl. Monginsidi, Sarae, Rasanae Bar., Bima, Nusa Tenggara Bar, Indonesia) “Received 08 February 2020, Accepted 14 Juny 2020, Published 27 July 2020" 


\section{Pendahuluan}

Perkembangan teknologi internet membuat penyebaran Word of Mouth tidak hanya terbatas pada komunikasi tatap muka, tetapi sudah berubah bentuk menjadi electronic Word of Mouth. eWOM memperkenalkan sebuah tempat yang sangat penting agar konsumen dapat memberikan opininya. Hal ini dianggap lebih efektif daripada WOM yang dilakukan secara offline, karena tingkat aksesibilitas dan jangkauannya yang lebih luas (Jalilvand, 2012)

Dengan semakin berkembangnya teknologi internet, perussahaan semakin diuntungkan. Perusahaan dapat mengambil keuntungan dari komunitas interaktif pelanggan untuk memulai dialog dengan para pelanggannya. Mereka dapat membangun jaringan untuk menciptakan electronic Word Of Mouth (eWOM) yang baik mengenai penawaran pasar mereka.

Kemajuan teknologi juga telah membawa perubahan besar pada konsumen, pasar dan marketing selama abad terakhir. Sejak awal tahun 2000, teknologi informasi telah memasuki pasar utama dan dikembangkan lebih jauh menjadi apa yang disebut sebagai new wave technology. (Hermawan Kertajaya, 2010) mengungkapkan bahwa new wave technology adalah teknologi yang memungkinkan konektivitas dan interaktivitas antar individu dan kelompok Word of Mouth (WOM) atau komunikasi dari mulut ke mulut dalam bidang pemasaran tidak asing lagi. Cara promosi ini sudah dikenal sejak ribuan tahun lalu, sebelum ilmu pemasaran telah demikian berkembang seperti sekarang. Ketika seseorang (pelanggan) merasa puas dalam membeli/ memakai jasa atau produk/barang di suatu tempat, ia cenderung akan menceritakan pengalamannya tersebut kepada orang lain, khususnya kepada orang terdekatnya.

Pada era digitalisasi seperti saat ini, WOM telah berubah nama menjadi e-WOM (electronic Word of Mouth). Memang ada perbedaan antara WOM dan e-WOM seperti yang disebutkan oleh berikut: 1) mereka berkomunikasi tanpa tatap muka; (2) informasi tersebut diberikan kepada penerima kembali tanpa meminta atau mencari. Namun, digitalisasi sebagai wujud dari perkembangan teknologi yang sangat pesat yang tujuan utamanya memberikan kemudahan dan efisiensi dari berbagai segi, seperti efisiensi tenaga, biaya, prosedur, dan lain-lain.

Pada saat produsen/penjual melakukan posting di facebook tentang informasi yang berkaitan dengan produk, maka teman facebook akan memberikan respon (melakukan like, comment, 
repost). Pada saat itu maka brand awareness produk akan meningkat. Hal ini juga terjadi pada brand image produk tersebut, akan terlihat baik atau buruk tergantung dari opini produk di media sosial facebook. Brand knowledge yang terdiri dari brand awareness dan brand image merupakan area utama dari e-WOM communication yang terjadi pada produk.

(Gurviez \& Korchia, 2003); (Ferrinadewi, 2008) menjelaskan tentang brand trust sebagai variabel psikologis yang mencerminkan jumlah akumulasi asumsi awal yang melibatkan kredibilitas, integritas, dan benevolence, yang dilekatkan pada merek tertentu. Faktor trust terhadap sebuah merek merupakan aspek krusial dalam pembentukan brand loyalty. Percaya pada merek sebagai kesediaan konsumen untuk mempercayai atau mengandalkan merek dalam situasi resiko dikarenakan adanya ekspektasi bahwa merek bersangkutan akan memberikan hasil positif (Tjiptono, Chandra, \& Andriana, 2008). Apabila efek dari Brand trust ini tidak dikendalikan dapat megakibatkan pertimbangan akan tingkat kepentingan kepuasan pelanggan yang berlebihan dalam mengembangkan komitmen konsumen terhadap produk (Ferrinadewi, 2008). Semakin tinggi kepuasan merek yang dialami pelanggan, semakin besar kemungkinan mereka akan melekat pada merek tersebut. Brand trust dengan tingkat yang lebih tinggi dapat diharapkan untuk mengarah pada brand attachment yang lebih kuat. Berdasarkan hasil penelitian (Chinomona., Maziriri, 2017) diketahui bahwa brand trust berpengaruhi secara signifikan terhadap brand attachment.

Brand attachment (keterikatan merek) didefinisikan oleh (Lombart, 2010) sebagai "variabel psikologi yang memperlihatkan suatu hubungan afektif dengan merek yang langgeng dan tak berubah (perpisahaan adalah menyakitkan) dan menunjukkan hubungan kedekatan secara psikologi dengan merek tersebut brand attachment terbentuk karena produsen/penjual melalui akun di facebook tersebut mampu menciptakan interaksi antara pengguna facebook dengan produk, sering memberikan reward kepada para konsumen melalui kuis-kuis atau tantangantantangan sehingga brand attachment konsumen terhadap produk melalui akun facebook tersebut dapat terbentuk.

\section{Kajian Literatur}

2.1. E-WOM

WOM adalah proses menyampaikan informasi dari orang ke orang dan memainkan peran utama dalam keputusan pembelian pelanggan (Richins dan Root-Shaffer, 1988); (Jansen, Zhang, Sobel, 
\& Chowdury, 2009). Selain itu, dalam jurnal tersebut juga disebutkan bahwa dalam situasi komersial, WOM melibatkan pelanggan untuk berbagi sikap, opini atau reaksi tentang bisnis, produk atau jasa dengan orang lain. WOM dapat memberikan pengaruh yang sangat kuat pada persepsi kosumen terhadap sebuah produk (Jalilvand, 2012). Fungsi WOM berdasarkan social networking dan trust adalah orang mengandalkan keluarga, teman dan orang lain dalam jaringan sosialnya. Penelitian ini juga menunjukkan bahwa orang lebih 18 tertarik pada pendapat orang di luar social network yang mereka miliki, misalnya seperti online reviews (Duana, Gub, \& Whinston, 2008). Bentuk ini dikenal sebagai online WOM (eWOM) atau electronic WOM (eWOM).

\subsection{Brand Trust}

Brand trust menurut Gurviez \& Korchia (2003) (dalam Ferrinadewi, 2008) merupakan variabel psikologis yang mencerminkan jumlah akumulasi asumsi awal yang melibatkan kredibilitas, integritas, dan benevolence, yang dilekatkan pada merek tertentu. Faktor trust terhadap sebuah merek merupakan aspek krusial dalam pembentukan brand loyalty. Percaya pada merek sebagai kesediaan konsumen untuk mempercayai atau mengandalkan merek dalam situasi resiko dikarenakan adanya ekspektasi bahwa merek bersangkutan akan memberikan hasil positif (Lau \& Lee, 1999 dalam Tjiptono, Chandra, \& Andriana, 2008). Brand trust memiliki peran penting bagi merek, karena kepercayaan akan membantu mengurangi pengorbanan waktu dan risiko konsumen terhadap merek (Kapferer, 2008). Apabila efek dari brand trust ini tidak dikendalikan dapat megakibatkan pertimbangan akan tingkat kepentingan kepuasan pelanggan yang berlebihan dalam mengembangkan komitmen konsumen terhadap produk (Ferrinadewi, 2008). Semakin tinggi kepuasan merek yang dialami pelanggan, semakin besar kemungkinan mereka akan melekat pada merek tersebut.

\subsection{Brand Attachment}

Brand attachment menurut Kapferer (2008) adalah bukti keinginan pelanggan untuk tetap menjalin hubungan yang langgeng dengan merek. Brand attachment dicirikan oleh kesetiaan, yang merupakan ukuran perilaku pembelian berulang. Attachment (keterikatan) paling tinggi bila pelanggan mempunyai preferensi yang kuat akan produk atau jasa tertentu dan dapat secara jelas membedakannya dari produk pesaing (Griffin, 2002). Attachment merupakan hal yang penting karena sebagai kekuatan hubungan kognitif dan afektif antara konsumen dan 
produk. Tingkat kesetiaan yang dirasakan pelanggan terhadap merek. Bentuk keterikatan yang kuat, kepatuhan, adalah penolakan konsumen untuk berubah dan kemampuan merek untuk menahan berita buruk seperti kegagalan produk atau layanan (Schmitt \& Rogers, 2008).

Tabel 1. Dimensi Variabel Ewom, Brand Trust, dan Brand Attachment

\begin{tabular}{|c|c|c|}
\hline & $e-W O M$ & $\begin{array}{l}\text { Platform assistance, Venting negative feelings, Concern for } \\
\text { Other Consumers, Extraversion/positive self enhancement, } \\
\text { Social benefits, Economic incentives, Helping the company, } \\
\text { Advice seeking }\end{array}$ \\
\hline $\begin{array}{l}\text { Variabel } \\
\mathrm{X}\end{array}$ & Brand Trust & Kpercayaan, dapat diandalkan, jujur, keamanan. \\
\hline $\begin{array}{l}\text { Variabel } \\
\text { Y }\end{array}$ & $\begin{array}{l}\text { Brand } \\
\text { Attachment }\end{array}$ & $\begin{array}{l}\text { brand-self connection(hubungan merek-diri) dan brand } \\
\text { prominence (kemenonjolan merek). }\end{array}$ \\
\hline
\end{tabular}

\section{Metode Penelitian}

Penelitian ini menggunakan pendekatan kuantitatif dengan metode survey. Menurut (Hartono, 2010) survei adalah metode pengumpulan data primer dengan memberikan pertanyaanpertanyaan kepada responden. Kuesioner digunakan untuk mengumpulkan data dari responden yaitu konsumen yang menggunakan Facebook dan pernah melakukan transaksi pembelian di media social Facebook di Kota Bima. Populasi dalam penelitian ini adalah masyarakat yang berada di Kota Bima. Teknik pengambilan sampel yang digunakan dalam penelitian ini adalah purposive sampling yaitu teknik pengambilan sampel dari populasi berdasarkan kriteria tertentu (Hartono, 2010). Jumlah sampel dalam yang diambil dalam penelitian ini adalah 100 responden (Amirullah, 2013), dengan kriteria pengguna facebook yang pernah membeli produk secara online di Kota Bima dan usia diatas 17 tahun karena dianggap mampu menjawab pernyataan dari kuesioner.

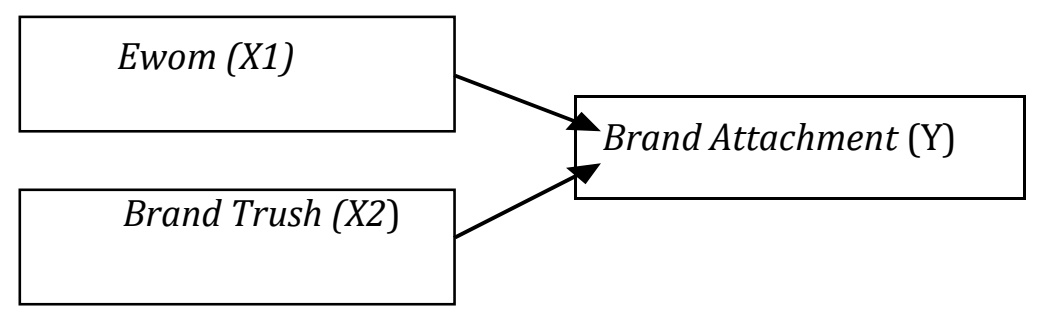

Keterangan :

$$
\text { :Pengaruh secara parsial }
$$

$\mathrm{H}_{1}$ : E-wom tidak berpengaruh secara positif terhadap Brand Attachment

$\mathrm{H}_{2}$ : Brand Trust berpengaruh secara positif terhadap Brand Attachment 


\section{Hasil Penelitian dan Pembahasan}

\subsection{Analisis Regresi Linier Berganda}

Pengujian hipotesis dalam penelitian ini menggunakan analisis regresi linier berganda dengan bantuan program SPSS 20.00 for Windows untuk mengetahui pengaruh variabel E-wom ( $\left.\mathrm{X}_{1}\right)$, dan Brand trust $\left(\mathrm{X}_{2}\right)$ terhadap Brand attachment (Y) secara parsial. Hasil uji regresi linier berganda dalam penelitian ini dapat dilihat pada tabel berikut:

Tabel 2 Hasil Uji Regresi Linier Berganda

\begin{tabular}{lccl}
\hline Variabel & $\begin{array}{l}\text { Standardi zed Coefficients } \\
\text { Beta }\end{array}$ & Sig & Keterangan \\
\hline e-WOM & .043 & .293 & Positif dan tidak signifikan \\
$\begin{array}{l}\text { Brand } \\
\text { Trust }\end{array}$ & .504 & .000 & Positif dan signifikan \\
\hline
\end{tabular}

Sumber: Data Primer, 2020

Berdasarkan hasil uji regresi linier berganda pada tabel 2, dapat dibuat persamaan dari hasil pengujian tersebut sebagai berikut:

$Y=6,422+0,043\left(X_{1}\right)+0,504\left(X_{2}\right)$

Persamaan diatas dapat dijelaskan sebagai berikut:

1) Variabel e-WOM mempunyai pengaruh positif sebesar 0,043 terhadap Brand Attachment

2) Variabel brand trust mempunyai pengaruh positif sebesar 0,504 terhadap Brand Attachment

Hal ini menunjukan bahwa semakin tinggi $e$-WOM dan brand trust suatu produk online maka akan meningkatkan brand attachment konsumen pada suatu produk yang dijual secara online di Kota Bima.

\subsection{Uji Signifikansi}

Uji signifikansi dimaksudkan untuk mengetahui seberapa jauh pengaruh variable $e$-WOM $\left(\mathrm{X}_{1}\right)$ dan brand trust $\left(\mathrm{X}_{2}\right)$ terhadap variabel brand attachment $(\mathrm{Y})$ secara parsial. Hasil uji t pada penelitian ini dapat diketahui bahwa pengaruh e-WOM $\left(\mathrm{X}_{1}\right)$ terhadap brand attachment $(\mathrm{Y})$ menunjukan nilai tidak signifikansi sebesar 0,293, karena memiliki nilai signifikansi t lebih besar dari taraf 5\% (>0,05). Variabel brand trust $\left(\mathrm{X}_{2}\right)$ terhadap brand attachment (Y) menunjukan nilai signifikansi sebesar 0,00 . Variabel brand trust $\left(\mathrm{X}_{2}\right)$ mempunyai nilai 
signifikansi t lebih kecil dari taraf 5\% $(<0,05)$. Hasil ini menunjukan bahwa variabel brand trust $\left(\mathrm{X}_{2}\right)$ berpengaruh positif dan signifikan terhadap brand attachment.

\subsection{Hasil Uji Hipotesis}

Tabel 3. Hasil Uji Hipotesis

\begin{tabular}{lrrl}
\hline Variabel & \multicolumn{1}{c}{ t-hit } & t-tab & Keterangan \\
\hline$e$-WOM & & & \\
& 1.058 & 1,988 & Tidak Berpengaruh \\
Brand Trust & 5.116 & 1,988 & Berpengaruh \\
\hline
\end{tabular}

Sumber: Data Primer, 2020

\subsection{Pengaruh Variabel X terhadap Variabel Y}

a). Pengaruh e-WOM terhadap Brand Attachment

Berdasarkan tabel hasil analisis regresi linier berganda menunjukan bahwa variabel $e$-WOM memiliki nilai thitung 1,058 dan t tabel 1,988 $(1,058<1,988)$ dengan signifikansi tersebut lebih besar dari taraf $5 \%(0,293>0,05)$, sehingga hipotesis hasil penelitian yang menunjukan bahwa variabel $e$-WOM tidak berpengaruh positif dan tidak signifikan terhadap brand attachment "di terima".

Dengan demikian dapat disimpulkan bahwa dalam penelitian ini dengan adanya $e$-WOM melalui facebook tidak dapat membentuk brand attachment konsumen dan produk online di Kota Bima. E-WOM yang dilakukan seharusnya dapat memberikan stimulus kepada konsumen untuk menarik minat tetapi gaya bahasa dan image yang ditampilkan belum memenuhi kriteria tersebut. Untuk itu para pengusaha yang menjual produk secara online khususnya di Facebook harus selalu beradaptasi dan menyesuaikan dengan selera dan keinginan konsumen agar menimbulkan brand attachment antara konsumen dan produk online.

\section{b). Pengaruh Brand Trust terhadap Brand Attachment}

Berdasarkan tabel hasil analisis regresi linier berganda menunjukan bahwa variabel brand trust memiliki nilai t hitung 5,116 dan t tabel 1,988 $(5,116>1,988)$ dengan nilai signifikan sebesar 0,00 . Nilai signifikansi tersebut lebih kecil dari taraf $5 \%(0,00<0,05)$. sehingga hipotesis hasil penelitian yang menunjukan bahwa variabel brand trust berpengaruh positif dan signifikan terhadap brand attachment "diterima". Dengan demikian dapat disimpulkan bahwa dengan 
adanya brand trust konsumen terhadap produk online maka akan membentuk dan meningkatkan brand attachment.

\section{Kesimpulan}

Variabel brand trust dipersepsikan dapat membentuk brand attachment antara konsumen dan produk online, sehingga para pengusaha Yang berjualan secara online harus fokus dalam mempertahankan dan meningkatkan brand trust konsumen atau masyarakat terhadap produk yang dijual secara online sehingga dapat menimbulkan pengalaman emosional yang positif, yang berdampak pada terbentuknya brand attachment antara konsumen dan produk online di Kota Bima. Brand trust yang diciptakan oleh para penjual online di Kota Bima sudah mampu menciptakan pengalaman positif pada diri konsumen sehingga telah membentuk brand attachment yang kuat.

\section{References :}

Amirullah. (2013). Metodologi Penelitian Manajemen. Malang: Bayumedia.

Chinomona, R., \& Maziriri, E.T. (2017). The influence of brand awareness, brand association and product quality on brand loyalty and repurchase intention: a case of male consumers for cosmetic brands in South Africa. Journal of Business and Retail Management Research (JBRMR). Vol. 12 Issue 1

Ferrinadewi, Erna. (2008). Merek dan Psikologi Konsumen. Yogyakarta: Graha Ilmu.

Griffin, Jill, (2002), Customer Loyalty, Menumbuhkan dan Mempertahankan Kesetiaan Pelanggan, Erlangga, Jakarta.

Hartono, Jogiyanto. (2010). Metodologi Penelitian Bisnis: Salah Kaprah dan PengalamanPengalaman. Edisi Pertama. BPFE. Yogyakarta

Hermawan Kertajaya. 2010. Grow with Character: The Model Marketing. Jakarta: PT. Gramedia Pustaka Utama

Jalilvand, R. (2012). The Effect of Electronic Word of Mouth on Brand Image and Purchase Intention. Marketing Intelegence and Planning , 460-476.

Jansen, B. J., Zhang, M., Sobel, K. \& Chowdury, A. (2009). Twitter Power: Tweets as Electronical Word of Mouth. Journal of The American Society for Information Science and Technology, 60 (11), pp. 2169-2188

Kapferer, Jean-Noel. (2008). New Strategic Brand Management: Creating And Sustaining Brand Equity Long Term 4th Edition. London and Philadelphia: Kogan Page Limited.

Klimchuck, Marianne R., \& Krasovec, Sandra A. 2012. Packaging Design: Successful Product Branding from Concept to Shelf, Second edition. New Jersey: Wiley

Louis, D. and Lombart, C. 2010. "Impact of Brand Personality on Three Major Relational Consequnces (Trust, Attachment, and Commitment to the Brand)", Journal of Product \& Brand Management, Vol. 19 No. 2, pp. 114-130

Ramadhani, Z.K, Pujiastuty, E.E, dan Utomo, H.J.N. 2019. "Pengaruh Brand Experience Dan Brand Trust Terhadap Brand Attachment Serta Brand Loyalty", Jurnal Administrasi Bisnis, Vol. 17 No. 1, pp. 47-57

Schmitt, Bernd H \& Rogers, David L. (2008). Handbook on Brand and Experience Management. United Kingdom: Edward Elgar Publishing Limited 
Ismunandar $^{\varpi_{1}}$, Sri Ernawati ${ }^{2}$

Pengaruh E-WOM Facebook dan Brand Trust terhadap Pembentukan Brand Attachment Produk Online di Kota Bima DOI : https://doi.org/10.37531/ecotal.v1i2.18

Tjiptono, Fandy, Gregorius Chandra dan Dadi Adriana. 2008. Pemasaran Strategik. Andi, Yogyakarta. 